\title{
Imaging of T cells in patients with recurrent glioblastoma
}

\author{
Sanjiv Sam Gambhir \\ Canary Center at Stanford for Cancer Early Detection, Palo Alto, Molecular Imaging Program at Stanford, Department of Radiology and Bio-X \\ Program, Stanford University, Stanford, CA, USA \\ Correspondence to: Sanjiv Sam Gambhir, MD, PhD. Molecular Imaging Program at Stanford, James H. Clark Center, 318 Campus Drive, Stanford, \\ CA 94305-5427, USA. Email: sgambhir@stanford.edu. \\ Response to: Miyazaki T, Aiyama H, Ishikawa E. CAR-T cell in vivo tracking method using PET scan with the reporter gene and new investigational \\ tracer [18F] FHBG. Transl Cancer Res 2017;6:S1103-5.
}

Submitted Aug 05, 2017. Accepted for publication Aug 15, 2017.

doi: $10.21037 /$ tcr.2017.08.27

View this article at: http://dx.doi.org/10.21037/tcr.2017.08.27

Immunotherapies including CAR-T cell therapies offer some new hope for treatment of various cancers. As with all therapies, individual patient optimization would be of great help to maximize the chance of success. Issues including: (I) earlier detection of aggressive cancers; (II) staging of the cancer to determine different sites of tumor involvement; (III) determination of likelihood of benefit from a given therapy; (IV) monitoring during or soon after completion of therapy to determine non-responders so that one can change to another therapeutic strategy early; (V) monitoring for recurrence of the cancer after initial treatment, are all in need of careful attention. For each of these approaches both in vitro diagnostics and in vivo imaging offer potential solutions for cancer diagnosis and management.

In the current work we wanted to specifically image CAR-T cells that arrived into tumor sites in recurrent glioblastoma (GBM) patients. Although there are several ways available to image the tumor itself including with $M R$, PET, and other approaches, there are no clinical strategies for imaging the immune system including CAR-T cells. By stably transfecting the CAR-T cells with the herpes simplex type 1 virus thymidine kinase (HSV1-tk) PET reporter gene, we were able to use an acycloguanosine derivative tracer $\left\{\left[{ }^{18} \mathrm{~F}\right]-\mathrm{FHBG}\right\}$ in order to specifically image the CAR-T cells. This is because $\left[{ }^{18} \mathrm{~F}\right]$-FHBG is near exclusively trapped through phosphorylation only in cells that express HSV1-tk and not mammalian thymidine kinase. The $\left[{ }^{18} \mathrm{~F}\right]-$ FHBG tracer does not cross the intact BBB so it is possible that some areas of the brain that have tumor cells are not able to be imaged for presence of CAR-T cells. However, most areas with GBM will have a broken $\mathrm{BBB}$ allowing the tracer to reach CAR-T cells that may have homed there. Ideally, a different tracer that crosses the intact BBB and can then be phosphorylated by HSV1-tk would be important to develop. Alternatively, a different PET reporter gene/ reporter probe combination in which the reporter probe (tracer) can cross the BBB may be worth exploring in future studies.

We have previously studied in detail the safety of $\left[{ }^{18} \mathrm{~F}\right]-$ FHBG tracer in human volunteers (1). As expected, there were no significant safety issues with the tracer because it is given in such low mass levels as are all PET tracers. This previously published study also allowed us to better understand radiation dosimetry to various organs with $\left[{ }^{18} \mathrm{~F}\right]$ FHBG. This and related early studies helped us to obtain US FDA approval for moving forward with this tracer in different gene and cell therapy applications.

The current pilot patient imaging study of CAR-T cells with $\left[{ }^{18} \mathrm{~F}\right]$-FHBG PET is limited by several issues. (I) It is only a pilot study in recurrent GBM patients and as such any conclusions are limited. Ideally, we will be able to do a larger study in GBM patients undergoing CAR-T cell therapy after initial diagnosis of GBM. (II) The change in PET signal pre- and post-administration of CAR-T cells is small. This can be further optimized by using a mutant HSV1-tk reporter gene that will trap more ${ }^{18} \mathrm{~F}-\mathrm{FHBG}$ per CAR-T cell leading to a greater change in PET signal. (III) Our quantitation techniques are based on total PET signal in a region of interest in the brain images. Future studies can improve this quantitation by formal tracer kinetic modeling (2) which will require blood sampling to obtain the input function and dynamic imaging of the 
brain to allow determination of a tissue time-activity curve. More rigorous quantitation may allow determination of the number of CAR-T cells that have arrived into a given region of the brain. (IV) Ideally we can eventually start to determine if imaging levels of CAR-T cells in a given patient is truly useful. Perhaps if not enough CAR-T cells are reaching the GBM one could do a repeat administration of the cells. It is also possible that imaging CAR-T cell levels will eventually found not be helpful if the levels of CAR-T cells don't correlate with eventual response to therapy or progression free survival.

Ideally as imaging techniques evolve one would be able to image different elements of the immune system with various strategies [reviewed in (3)]. Additionally, it would be ideal to image CAR-T cells and other related therapies without pre-labeling the cells with a reporter gene. This requires having a tracer that can image a target that is relatively specific to the cells of interest. For example, we have recently imaged activated T cells using a small molecule tracer that is relatively specific for activated $\mathrm{T}$ cells due to up-regulation of a key intracellular enzyme. We tested this approach in graft $v s$. host disease (GVHD) and then also translated the tracer to normal human volunteers (4). Other similar approaches targeting various immune cell specific targets may allow additional strategies to optimizing immune therapies. These approaches will be particularly important when one does not have access to specific immune cells ex vivo that are being injected into the subject of interest.

In summary, the current work has imaged CAR-T cells in recurrent GBM patients with PET imaging in a pilot feasibility study. Although much work still remains, there is hope that immunotherapies combined with molecular imaging will someday help to better manage cancer patients.

\section{Acknowledgments}

Funding: None.

\section{Footnote}

Provenance and Peer Review: This article was commissioned and reviewed by the Section Editor Xianxin Qiu (Department of Neurosurgery, the Children's Hospital of Medical College, Zhejiang University, Hangzhou, China).

Conflicts of Interest: Dr. Gambhir is co-founder of CellSight Inc., which develops and clinically translates strategies to image cell transplantation and trafficking in living subjects. As co-founder he holds significant equity in CellSight Inc.

Ethical Statement: The authors are accountable for all aspects of the work in ensuring that questions related to the accuracy or integrity of any part of the work are appropriately investigated and resolved.

Open Access Statement: This is an Open Access article distributed in accordance with the Creative Commons Attribution-NonCommercial-NoDerivs 4.0 International License (CC BY-NC-ND 4.0), which permits the noncommercial replication and distribution of the article with the strict proviso that no changes or edits are made and the original work is properly cited (including links to both the formal publication through the relevant DOI and the license). See: https://creativecommons.org/licenses/by-nc-nd/4.0/.

\section{References}

1. Yaghoubi S, Barrio JR, Dahlbom M, et al. Human pharmacokinetic and dosimetry studies of [(18)F]FHBG: a reporter probe for imaging herpes simplex virus type1 thymidine kinase reporter gene expression. J Nucl Med 2001;42:1225-34.

2. Gambhir SS. Chapter 2: Quantitative Assay Development for PET. In: Phelps ME. editor. Positron Emission Tomography. New York: Raven Press, 2004:125-216.

3. Kurtz DM, Gambhir SS. Tracking cellular and immune therapies in cancer. Adv Cancer Res 2014;124:257-96.

4. Ronald JA, Kim BS, Gowrishankar G, et al. A PET Imaging Strategy to Visualize Activated T Cells in Acute Graft-versus-Host Disease Elicited by Allogenic Hematopoietic Cell Transplant. Cancer Res 2017;77:2893-902.
Cite this article as: Gambhir SS. Imaging of T cells in patients with recurrent glioblastoma. Transl Cancer Res 2017;6(Suppl 7):S1291-S1292. doi: 10.21037/tcr.2017.08.27 